\title{
Self-association of free base porphyrins with aminoacid substituents in AOT reverse micelles
}

\author{
Suzana M. Andrade ${ }^{\mathrm{a}, *}$, Catarina Teixeira ${ }^{\mathrm{a}}$, Denisio M. Togashi ${ }^{\mathrm{a}}$, \\ Sílvia M.B. Costa ${ }^{\mathrm{a}, *}$, Abílio J.F.N. Sobral ${ }^{\mathrm{b}}$ \\ ${ }^{a}$ Centro de Química Estrutural, Complexo 1, Instituto Superior Técnico, 1049-001 Lisboa, Portugal \\ ${ }^{\mathrm{b}}$ Departamento de Química-FCTUC, Universidade de Coimbra, 3004-535 Coimbra, Portugal
}

Available online 21 November 2005

\begin{abstract}
The aggregation properties of aminosulfonyl porphyrins with aminoacid substituents: methionine with the acid function methylated, $\mathrm{PMet}_{\mathrm{CH}_{3}}$; phenylalanine, PPhe; attached to the para positions of the meso phenyls of the porphyrin, was followed in organic solvents, water-dioxane mixtures and in reverse micelles of aerosol OT (AOT RM), using absorption, steady-state and time-resolved fluorescence. In AOT RM in the absence of water, both porphyrins are mainly present as monomers with the Soret band around $420 \mathrm{~nm}$ and with emission maxima around 649 and $717 \mathrm{~nm}$. In the presence of water accounted for by parameter $\omega_{0}, \omega_{0}=\left[\mathrm{H}_{2} \mathrm{O}\right] /[\mathrm{AOT}]$, the solubility of both porphyrins is enhanced and followed by important spectral changes similar to those observed in the solvent mixtures: new maxima in absorption around $405 \mathrm{~nm}$ and in emission around $670 \mathrm{~nm}$. A concomitant increase of the aggregates' contribution is found for $\mathrm{PMet}_{\mathrm{CH}_{3}}$, whereas for PPhe the effect is much more pronounced until $\omega_{0}=10$, above which a de-aggregation process occurs, due to competition between intra- and inter-molecular interactions. The small resonant light scattering signals observed points to the existence of aggregates of small dimensions whose nature is discussed in terms of exciton theory.
\end{abstract}

(c) 2005 Elsevier B.V. All rights reserved.

Keywords: Porphyrin; Sulfonamide; Reverse micelle; Aggregation; Fluorescence

\section{Introduction}

The control of dye association in a special organized geometry or in spontaneous self-assembled systems is of vital importance due to the large impact in many fields of chemistry, physics, and medicine [1]. Porphyrin is one of the most important dyes studied in the context of self-assembly induced by non-covalent interactions. Porphyrin aggregates play specific roles in photosynthetic plants and organisms [2] and have potential uses as nonlinear optical materials [3]. It is well known that hydrophobic porphyrins undergo aggregation processes in water-rich media [4]. Dimers and other aggregates in general exhibit low singlet oxygen yield, canceling their PDT therapeutic effectiveness [5]. Depending on the geometrical arrangement of the chromophores, the exciton theory developed by Kasha [6] predicts the occurrence of hypsochromic or bathochromic shifts for the relevant absorption bands, in the case of $\mathrm{H}$ - (face-to-face) or

\footnotetext{
* Corresponding authors. Tel.: +35121 8419271; fax: +351 218464455 .

E-mail address: sbcosta@mail.ist.utl.pt (S.M.B. Costa).
}

J-type (side-by-side) interactions, respectively. A large body of investigation in this matter has been devoted to the water-soluble ionic meso-tetrakis(4-sulfonatophenyl)porphyrin, TSPP, due to the reported self-aggregation in acidic conditions [7] forming ordered nanowires of J-aggregates with potential applications in optoelectronics [8]. More recently, we have shown that its encapsulation in aerosol OT reverse micelles (AOT RM) allowed us to modulate TSPP aggregation since changes in the ratio $\omega_{0}$ make possible the control of the inner pool dimensions. Both $\mathrm{H}$ - and J-type of aggregates could be promoted, the former at low $\omega_{0}$ (probably dimers) whereas at high $\omega_{0} \mathrm{~J}$-aggregation was favoured and its size increased with the pool size (i.e. with $\left.\omega_{0}\right)$.

A new class of sulfonamide meso-tetraphenylporphyrin derivatives with PDT activity have been synthesized [9]. The sulfonamide group is known to be present in many drugs with bactericide and chemotherapeutic applications [10]. Molecular association of compounds with sulfonamide group was reported as being promoted by intramolecular hydrogen bonding whilst dissociation seems to be favored by intermolecular hydrogen bonding in protic solvents [11]. In a recent 
paper, Togashi et al. [12] explored these sulfonamide porphyrin derivatives with different alkyl chain lengths, $\mathrm{PC} n(n=0,4$, 12) which showed a complex pattern of self-aggregation in AOT reverse micelles [12b] dependent on $\omega_{0}$ and alkyl chain length.

In this study, we attempted to elucidate the relationship between the microenvironments provided by AOT RM and the properties of self-aggregation of newly synthesized sulfonamide porphyrins with aminoacid phenylalanine (Phe) and methionine (Met) groups, the latter with the acid function methylated. Considering the important roles performed by proteins bearing a porphyrinic prosthetic group, as in the case of oxygen transport to cells by hemoglobulin or in electron transport during respiration process by cytochromes, it is important to study the molecular interactions involved in these systems of AOT RM viewed as model candidate to mimic the water pockets often found in proteins, membranes or mitochondria. The spectral characteristics of aforementioned porphyrins as well as time-resolved data were compared to data obtained in dioxane-water mixtures, which are commonly used to sense polarity changes in the photophysics of a probe molecule [13].

\section{Experimental}

\subsection{Materials}

The porphyrin derivatives, $\mathrm{PMet}_{\mathrm{CH}_{3}}, \mathrm{PPhe}_{\mathrm{CH}_{3}}$ and PPhe, were synthesized as described elsewhere [9]. Sodium 1,4-bis(2ethylhexyl)sulfosuccinate (AOT) (catalogue no. D-4422) $\geq 99 \%$ purity was purchased from Sigma (St. Louis, MO) and used without further purification. Buffer solutions were made up with bidistilled water, following the recommended procedures. The buffer concentration (citrate-phosphate for $\mathrm{pH}$ 3-6 and carbonate for $\mathrm{pH}$ 9) employed was $25 \mathrm{mM}$. All solvents were spectroscopic grade.

\subsection{Preparation of samples}

A stock solution of AOT/iso-octane $(0.1 \mathrm{M})$ was prepared and checked for fluorescence emission which was negligible at the experimental conditions used. Reverse micelle solutions were then prepared by direct addition of bidistilled water into the surfactant/hydrocarbon mixture at different molar ratios, i.e. $\omega_{0}$, and left to stabilize ca. $12 \mathrm{~h}$. Concentrated stock solutions of each porphyrin were prepared in chloroform (acetone for PPhe). The incorporation of each porphyrin in the micellar aggregate solutions was achieved by adding small aliquots of the stock solution and bubbling a stream of $\mathrm{N}_{2}$ to remove the solvent. The porphyrin thin films formed in the flask wall were dissolved in the AOT reverse micelle containing the appropriate amount of water. The solutions were agitated until total transparency and left overnight at room temperature before measurements were carried out. The final concentration of porphyrin was kept small $(1 \mu \mathrm{M})$ for both steady-state and time-resolved fluorescence measurements.

\subsection{Methods}

A Jasco V-560 spectrophotometer was employed in UV-vis absorption measurements. Fluorescence measurements were recorded with a Perkin-Elmer LS 50B spectrofluorimeter. Bandpass slits of $7.5 \mathrm{~nm}$ were used for both fluorescence excitation and emission monitoring TSPP. The instrumental response at each wavelength was corrected by means of a curve obtained using appropriate fluorescence standards together with the one provided with the instrument. Resonant light scattering spectra (RLS) were carried out by synchronous excitation and emission scanning in the right angle geometry and corrected by subtracting the correspondent blank sample. The sample holder of both instruments was thermostated at $25^{\circ} \mathrm{C}$, and all the measurements were taken using quartz cuvettes with $10 \mathrm{~mm}$ path lengths. Fluorescence decays were obtained with a timecorrelated single-photon counting (TC-SPC) technique using commercial equipment Microtime 200 from Picoquant $\mathrm{GmbH}$ described elsewhere [14]. Briefly, the measurements are performed in front-face geometry and the backscattered light is attenuated through the use of appropriate filters. Excitation was achieved using a pulsed laser diode head at $405 \mathrm{~nm}$, with a repetition rate of $10 \mathrm{MHz}$. The maximum output power is $0.4 \mathrm{~mW}$ and a minimum pulse width of $54 \mathrm{ps}$ is obtained. A band-pass filter with a transmission window in the range of $600-800 \mathrm{~nm}$ was used to eliminate backscattered light in the photomultiplier tube from Picoquant (model PMA-182). Data acquisition can be recorded with 4096 channels per range with a time increment smaller than 40 ps. Data analysis was performed by a deconvolution method using a nonlinear least-squares fitting program, based on the Marquardt algorithm. The goodness of the fit was evaluated by the usual statistical criteria and by visual inspection of the distribution of weighted residuals and the autocorrelation function.

\section{Results}

\subsection{Solvatochromism of porphyrins}

The influence of solvent nature in the electronic absorption and fluorescence spectra of these aminosulfonyl porphyrins (Scheme 1) was studied. The shape of the absorption and emission bands for these porphyrins does not depend on the substituent groups. In agreement with data previously reported for other porphyrins containing aminosulfonyl groups in the four meso-positions [12a], a red-shift of the Soret band relatively to that of TPP was detected. Usually, the presence of substituent groups in TPP leads to a polarizability increase and consequently red-shifts on the electronic transitions are detected.

The range of spectral shifts is small and hence, the data extracted from solvatochromic models applied to these molecules will have reduced accuracy and considerable uncertainty. Nevertheless, attempts were made to predict the experimental spectral shifts using theoretical models [12a,15].

For three aminosulfonyl porphyrins with aminoacid substituents the correlations are almost identical for all the models tested, which must be related to the fact that porphyrins being 


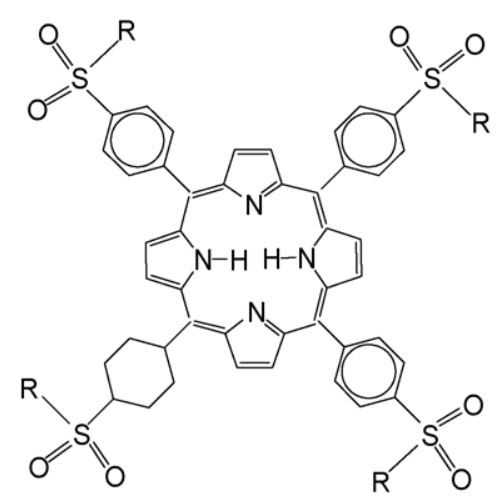<smiles>CNC(CCSC)C(C)=O</smiles><smiles>[R]OC(=O)C(Cc1ccccc1)NC</smiles>

Scheme 1.

centrosymmetric molecules without dipolar moment will essentially show a correlation of the electronic spectra with $f\left(n^{2}\right)[16]$, Fig. 1. Therefore, the dispersive forces are the main interactions responsible for the red-shift and no relevant dipolar or quadrupolar interactions between porphyrins and solvent molecules were observed.

These derivatized porphyrins are only scarcely water-soluble (porphyrins with methylated aminoacid group are virtually insoluble in water at the experimental conditions used, therefore no further studies with $\mathrm{PPhe}_{\mathrm{CH}_{3}}$ will be reported in this paper). Under neutral pH conditions, PPhe bears no charges and its solubility is quite marginal. The band profile is broad indicating the presence of aggregates and this solvent was obviously discarded from the correlations but prompt us to explore the effect of different water concentrations present in dioxane-water mixtures.

\subsection{Self-aggregation in dioxane-water mixtures}

The absorption and emission spectra of $\mathrm{PMet}_{\mathrm{CH}_{3}}$ were collected in a broad range $(0-52.7 \mathrm{M})$ of water concentration (this upper limit is determined by the porphyrin solubility in water). As the water fraction is increased $\left(x_{\mathrm{w}}<0.96\right)$ a concomitant blue shift of both the Soret absorption and fluorescence bands could be detected. The full width at half maximum of the Soret absorption band remained unchanged $\left(\mathrm{fwhm}=775.6 \mathrm{~cm}^{-1}\right)$. At higher water proportions a much larger blue shift occurs followed by broadening $\left(\mathrm{fwhm}=1917-2586 \mathrm{~cm}^{-1}\right.$ ) of the absorption band (to the blue and to the red), and strong hypochromicity, Fig. 2A. In turn, fluorescence emission is strongly quenched by water addition and a red-shift of the emission is detected together with some broadening. These aspects put into evidence a selfaggregation process induced by the low solubility in water. This is confirmed by the differences obtained in excitation spectra of $\mathrm{PMet}_{\mathrm{CH}_{3}}$ (data not shown): (a) at high Dx fractions spectra obtained with emission at 650 or $670 \mathrm{~nm}$ are slightly broader than absorption and red-shifted, (b) whereas at high water fractions Soret absorption band is much broader than in excitation, (c) at all Dx fractions tested the Soret band got broader when collected more to the red of the emission band (i.e. from 640 to $670 \mathrm{~nm})$, (d) finally, the difference between absorption and excitation spectra is more important in the blue part of the Soret band implying that different type of aggregates are formed $(\mathrm{H}-$ type in the blue and J-type in the red) and that the former are not emissive in contrast to the latter (see Section 4).

A spectral decomposition of the Soret band with a sum of two Gaussian functions was attempted and its dependence on the Onsager function for these mixtures is represented in Fig. 3. The use of the aforementioned solvatochromic models put into evidence a similar pattern of spectral shifts on the solvent properties, the main dependence being on $f\left(n^{2}\right)_{\text {mixt }}$ [17] as in the case of neat solvents. The correlation is nearly linear for mixtures lower than $x_{\mathrm{H}_{2} \mathrm{O}}=0.95$, but aggregation in water predominates above this molar fraction. Fluorescence emission data shows features similar to the currently described pattern (data not shown).
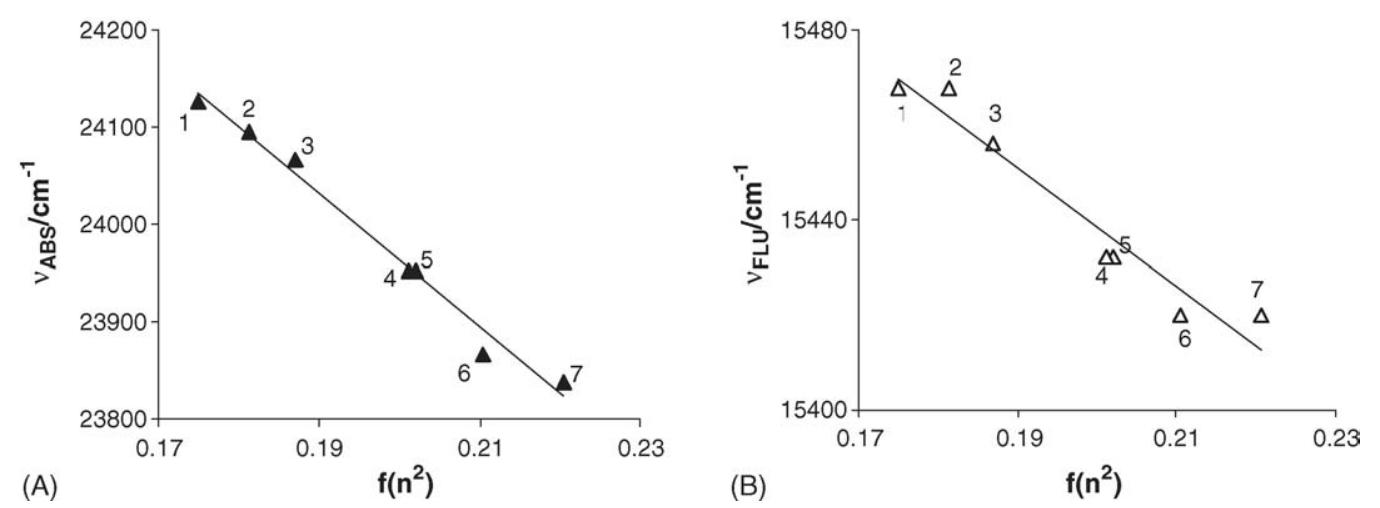

Fig. 1. Correlation of the Onsager function, $f\left(n^{2}\right)=\left(n^{2}-1\right) /\left(2 n^{2}+1\right)$, with the Soret band (A) and $Q(0,0)$ fluorescence (B) shifts of PMet $\mathrm{CH}_{3}(1$, acetonitrile; 2 , ethanol; 3 , acetone; 4 , hexanol; 5 , dioxane; 6 , chloroform; 7 , dimethylsulfoxide). 

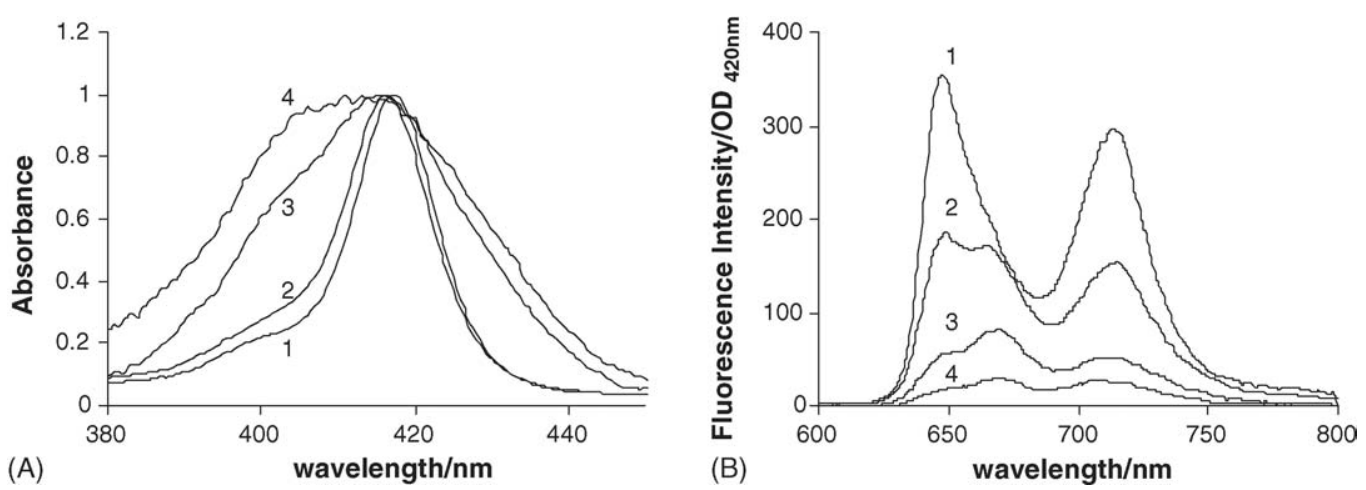

Fig. 2. (A) Absorption in the Soret region and (B) fluorescence emission of $\mathrm{PMet}_{\mathrm{CH}_{3}}$ in different water molar fractions in aqueous dioxane mixtures $\left(x_{\mathrm{w}}\right)$ : 1,0 ; 2 , $0.93 ; 3,0.96 ; 4,0.99\left(\lambda_{\mathrm{exc}}=420 \mathrm{~nm} ;\left[\mathrm{PMet}_{\mathrm{CH}_{3}}\right]=1 \mu \mathrm{M}\right)$.

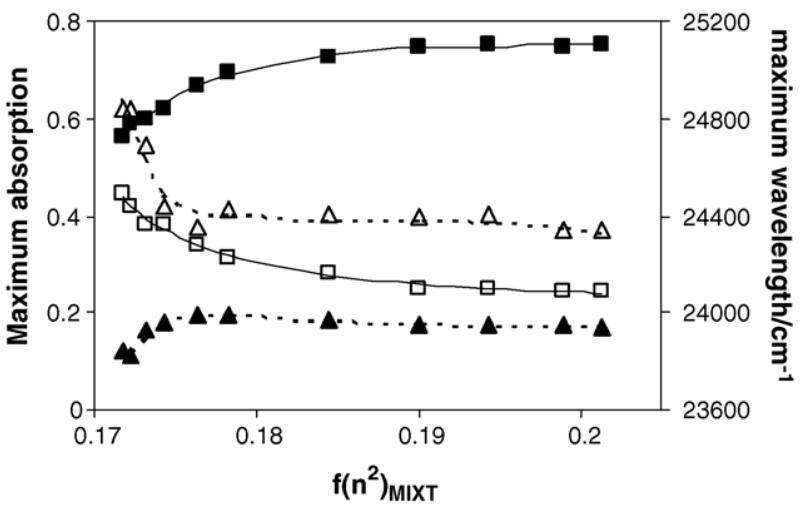

Fig. 3. Dependence of spectral decomposition parameters using a sum of two Gaussian functions (normalized fractional absorption of component: 1, $\mathbf{\square}, 2$, $\square$ and wavelength of maximum absorption of component: $1, \boldsymbol{\Lambda}, 2, \Delta$ ) on the Onsager function of the water-dioxane mixtures.

Fluorescence lifetimes for this class of porphyrins were measured both in neat solvents and in Dx-water mixtures, see Table 1. Interestingly, a monoexponential fluorescence decay was never obtained.

For neat solvents and for mixtures up to $x_{\mathrm{H}_{2} \mathrm{O}}$ lower than 0.96 two exponential decays were obtained. In Dx-water mixtures at high water fractions, a very short component was detected $\tau_{3}=0.340 \mathrm{~ns}$ which prevailed over the remainder at $x_{\mathrm{H}_{2} \mathrm{O}}>0.975$. The long lifetime obtained resemble that of TPP in toluene [18] and may therefore be assigned to the monomer in apolar medium.

The study in water was only possible for PPhe and the $\mathrm{pH}$ effect was followed at $\mathrm{pH} 3$ (pyrrolic N's are protonated), $\mathrm{pH} 6$ (neutral species) and pH 9 (tetra-anionic species), see Table 2. The components obtained for the neutral solution are in agreement with those obtained for the Dx-water mixtures at the highest water content studied which stresses the quenching effect by water and that the shortest component comes from specific interaction with water. At higher $\mathrm{pH}$, the contributions from the longer and intermediate components as well as lifetimes increase to values close to those obtained in organic solvents. Nevertheless, the shorter component is still detected but comparatively to $\mathrm{pH} 6$ it now contributes to a much less extent to the overall decay $(\sim 80$ to $\sim 39 \%)$. In conditions of low $\mathrm{pH}$, a strong quenching effect occurs and the decay is dominated $(\sim 88 \%)$ by the short-lived component ( $\tau=98 \mathrm{ps}$ ), while other components of 4.39 and $0.9 \mathrm{~ns}$ are also obtained. The acid form of another derivative of TPP, TSPP, has a lifetime of $3.8 \mathrm{~ns}$ when protonated in the pyrrolic N. By analogy, we think it is reasonable to assume that a lifetime of $4.39 \mathrm{~ns}$ for PPhe could stand for the similar species.

\subsection{AOT reversed micelles}

\subsubsection{Dependence on $\omega_{0}$}

The solubility of all tested porphyrins is very low in these systems, especially in the absence of water. Since these molecules are virtually insoluble in iso-octane at the concentrations studied, they will interact mainly with the surfactant headgroups.

3.3.1.1. $\mathrm{PMet}_{\mathrm{CH}_{3}}$. Absorption of $\mathrm{PMet}_{\mathrm{CH}_{3}}$ strongly increases with water content in AOT RM, but no changes on the spectral width at half maximum are detected nor there is a significant shift in the Soret band $\left(\lambda_{\max }=417.5-418 \mathrm{~nm}\right)$ and the spectra also resemble that in solvents like DMSO or Dx. Although there are no shifts detected in fluorescence either, a band broadening is observed with a shoulder $(\sim 670 \mathrm{~nm})$ growth upon increase of water the content, Fig. 4B. This shoulder had already been found in the Dx-water mixtures at high water contents. At low $\omega_{0}$, excitation spectra obtained at 640 or $720 \mathrm{~nm}$ give similar Soret bands which in turn are alike to the corresponding absorption

Table 1

Fluorescence lifetime of $\mathrm{PMet}_{\mathrm{CH}_{3}}$ in water-dioxane mixtures of varying molar fraction, $\lambda_{\text {exc }}=405 \mathrm{~nm}$

\begin{tabular}{lllllll}
\hline$x_{\mathrm{H}_{2} \mathrm{O}}$ & $A_{1}$ & $\tau_{1}(\mathrm{~ns})$ & $A_{2}$ & $\tau_{2}(\mathrm{~ns})$ & $A_{3}$ & $\tau_{3}(\mathrm{~ns})$ \\
\hline $0.00-0.82$ & $0.12-0.14$ & 4.01 & $0.86-0.88$ & 11.70 & - & - \\
$0.83-0.96$ & $0.08-0.11$ & 2.40 & $0.89-0.92$ & 12.10 & - & - \\
$0.97-0.99$ & 0.14 & 2.40 & $0.60-0.07$ & 10.50 & $0.26-0.79$ & 0.340 \\
\hline
\end{tabular}


Table 2

Triexponential fitting to fluorescence decays of $\mathrm{PMet}_{\mathrm{CH}_{3}}$ and PPhe in AOT RM at different water contents $\left(\lambda_{\text {exc }}=405 \mathrm{~nm}\right.$, band pass filter $\left.=600-800 \mathrm{~nm}\right)$

\begin{tabular}{|c|c|c|c|c|c|c|c|c|}
\hline Porphyrin & $\omega_{0}$ & $A_{1}$ & $\tau_{1}(\mathrm{~ns})$ & $A_{2}$ & $\tau_{2}(\mathrm{~ns})$ & $A_{3}$ & $\tau_{3}(\mathrm{~ns})$ & $\chi^{3}$ \\
\hline \multirow[t]{5}{*}{ PMet $_{\mathrm{CH}_{3}}$} & 0 & 0.750 & 11.51 & 0.250 & 2.85 & - & - & 1.025 \\
\hline & 4 & 0.530 & 11.57 & 0.220 & 2.73 & 0.250 & 0.330 & 1.038 \\
\hline & 8 & 0.490 & 11.61 & 0.340 & 2.62 & 0.180 & 0.390 & 1.058 \\
\hline & 10 & 0.460 & 11.62 & 0.330 & 2.64 & 0.210 & 0.410 & 1.044 \\
\hline & 30 & 0.510 & 11.75 & 0.310 & 2.62 & 0.180 & 0.290 & 1.006 \\
\hline \multirow[t]{5}{*}{ PPhe } & 0 & 0.745 & 11.20 & 0.255 & 2.45 & - & - & 1.050 \\
\hline & 6 & 0.660 & 11.27 & 0.120 & 2.22 & 0.220 & 0.190 & 1.075 \\
\hline & 10 & 0.630 & 11.24 & 0.160 & 2.05 & 0.210 & 0.207 & 1.089 \\
\hline & 18 & 0.450 & 10.83 & 0.300 & 2.42 & 0.250 & 0.389 & 1.077 \\
\hline & 30 & 0.250 & 10.05 & 0.490 & 2.24 & 0.260 & 0.309 & 1.053 \\
\hline \multirow[t]{3}{*}{ PPhe } & Water, pH 3 & 0.073 & 4.39 & 0.049 & 0.890 & 0.878 & 0.098 & 1.152 \\
\hline & Water, pH 6 & 0.110 & 9.80 & 0.100 & 0.985 & 0.790 & 0.090 & 1.130 \\
\hline & Water, pH 9 & 0.455 & 11.50 & 0.156 & 3.06 & 0.389 & 0.330 & 1.090 \\
\hline
\end{tabular}
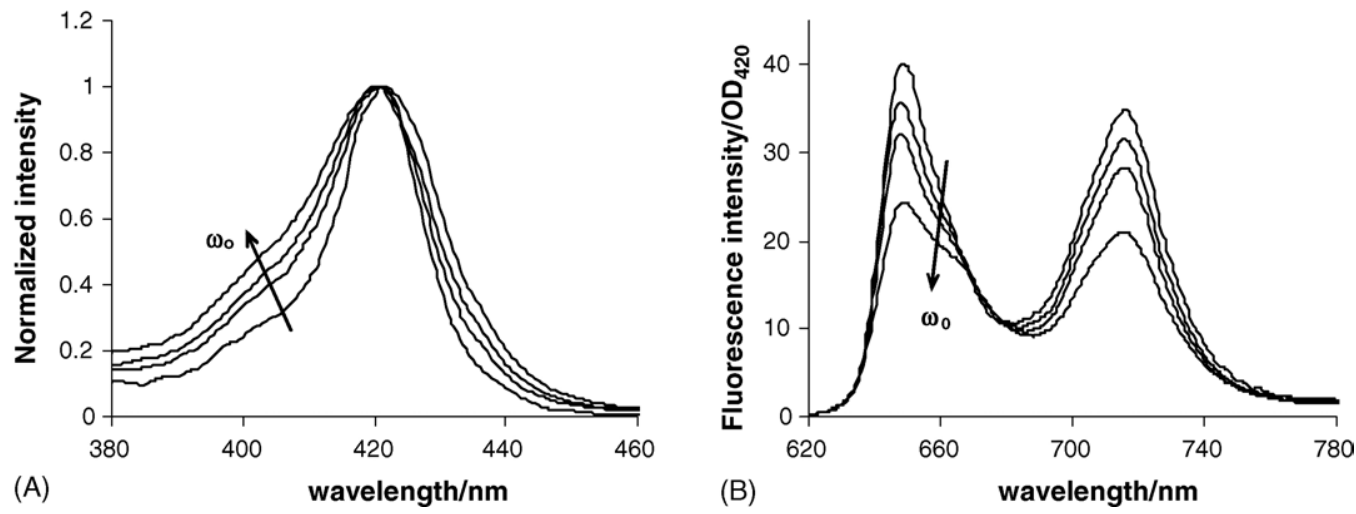

Fig. 4. Fluorescence excitation (A) and emission (B) spectra of $\mathrm{PMet}_{\mathrm{CH}_{3}}$ in AOT RM at different $\omega_{0} 0-40\left(\lambda_{\text {exc }}=420 \mathrm{~nm} ; T=298 \mathrm{~K} ;\left[\mathrm{PMet} \mathrm{CH}_{3}\right]=1 \mu \mathrm{M}\right)$.

band, but a broader one is observed when excitation spectra are obtained at $665 \mathrm{~nm}$ Fig. 4A. This seems to confirm the tendency of $\mathrm{PMet}_{\mathrm{CH}_{3}}$ to self-aggregate in the presence of water.

These differences increase with the water increase, as we may see from Fig. 5, where a plot of absorbance at $405 \mathrm{~nm}$ or intensity at $670 \mathrm{~nm}$ show that the main differences occur up to $\omega_{0}=10$ above which a plateau is reached.

This type of behavior is common in these systems and points out the competition between the probe and water for hydration of

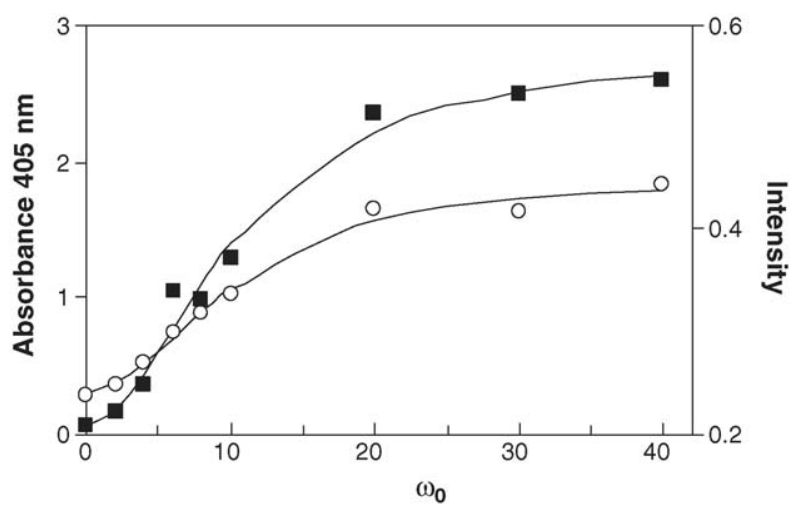

Fig. 5. Dependence of absorption (OD at $405 \mathrm{~nm}$, $\mathbf{0})$ and fluorescence excitation (intensity at $405 \mathrm{~nm}, \bigcirc$ ) on water content for $\mathrm{PMet}_{\mathrm{CH}_{3}}$ in AOT RM.
AOT headgroups. Hence, with the addition of water the probe partitions between the outer and the inner interface richer in water where $\mathrm{PMet}_{\mathrm{CH}_{3}}$ aggregates prevail. Both absorption and fluorescence data can provide a means to calculate an equilibrium constant defined as $K_{\mathrm{p}}=[\mathrm{P}]_{\mathrm{w}} /[\mathrm{P}]_{\mathrm{i}}\left[\mathrm{H}_{2} \mathrm{O}\right]^{b}$ through Eq. (1) previously introduced $[13 \mathrm{c}, 19]$ :

$\Psi^{\lambda}=\frac{\Psi_{i}^{\lambda}+\Psi_{w}^{\lambda} K_{\mathrm{p}}\left[\mathrm{H}_{2} \mathrm{O}\right]^{b}}{1+K_{\mathrm{p}}\left[\mathrm{H}_{2} \mathrm{O}\right]^{b}}$

where $\Psi^{\lambda}$ represents the absorbance or the fluorescence intensity obtained at a given wavelength $(\mathrm{OD}$ at $405 \mathrm{~nm}$; ratio of fluorescence intensity emission at $665: 650 \mathrm{~nm}$ obtained with excitation wavelength fixed at $420 \mathrm{~nm}$ and fluorescence intensity at $405 \mathrm{~nm}$ obtained with emission wavelength fixed at $665 \mathrm{~nm}$ ); $i$ and $w$ stand for the two possible locations for the porphyrin and $b$ represents the number of water molecules needed to displace the probe between those places. A common value for $K_{\mathrm{p}}=0.95 \pm 0.05 \mathrm{M}^{-1}$ was obtained while $b=2.0 \pm 0.1$ which confirms that water is involved in the process, but this porphyrin locates preferentially at the interface.

Fluorescence decays obtained upon excitation at $405 \mathrm{~nm}$ were best fitted with a sum of three exponentials, Table 2 . The long-lived component $\tau_{1}=11 \mathrm{~ns}$ and the intermediate one $\tau_{2}=2.4 \mathrm{~ns}$ increase with water addition and a similar 

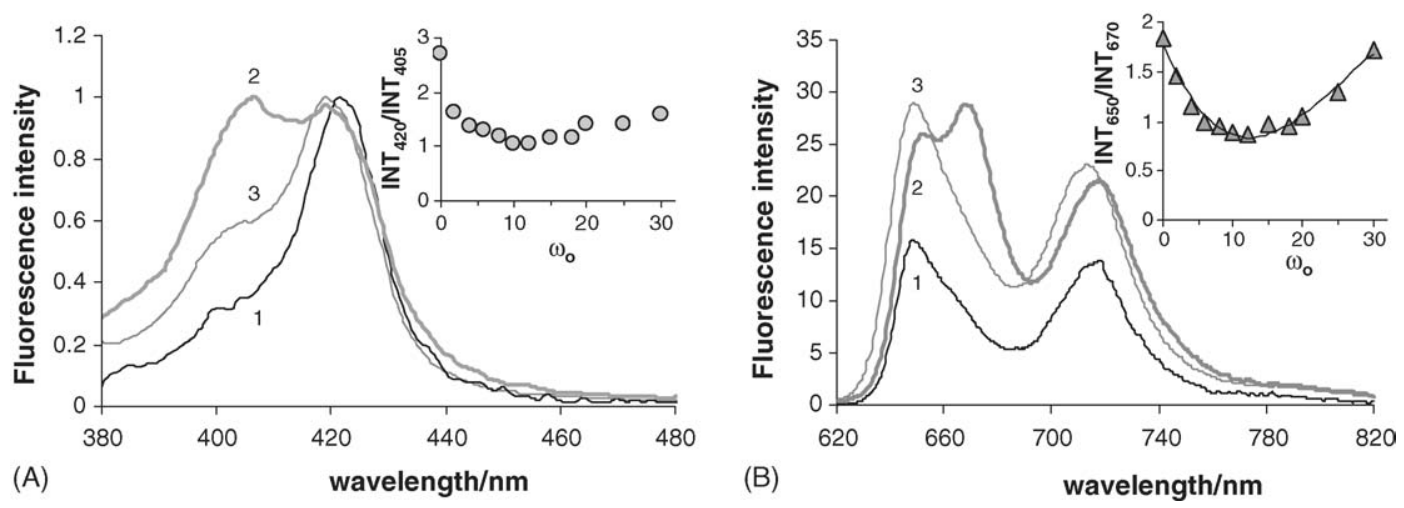

Fig. 6. Fluorescence excitation (A) and emission (B) spectra of PPhe in AOT RM at: 1, $\omega_{0}=0 ; 2, \omega_{0}=10 ; 3, \omega_{0}=30$. Inset (A) dependence of intensity ratio 420:405 nm on water content. Inset (B) dependence of intensity ratio $650: 670 \mathrm{~nm}$ on water content $\left(\lambda_{\mathrm{exc}}=420 \mathrm{~nm} ;[\mathrm{PPhe}]=1 \mu \mathrm{M} ;[\mathrm{AOT}]=0.1 \mathrm{M}\right)$.

trend is observed for the same $\left[\mathrm{H}_{2} \mathrm{O}\right]$ with that of Dx-water mixtures.

However, the contribution of this component to the overall decay is almost half in AOT $(\sim 45 \%)$ as compared to the mixtures (86\%). In the case of RM, the short-lived component $\tau_{3}=0.3 \mathrm{~ns}$ detected only in water or at very high water fractions in the mixtures, has an important contribution $\left(A_{3}=10-30 \%\right)$, probably due to the fact that $\mathrm{PMet}_{\mathrm{CH}_{3}}$ is soluble in Dx but not in iso-octane and therefore in these RM the porphyrin locates in an environment sensing higher local water concentrations than in the Dx-water mixtures.

3.3.1.2. PPhe. In the absence of water, the fluorescence spectrum of PPhe is mainly due to the monomeric species. Differences between the absorption and excitation spectra in the Soret band region also point to the existence of non-fluorescent aggregates absorbing both in the red and in the blue region of that band. These differences could not be found in solvents like DMSO or Dx.

As water is added $\left(\omega_{0}=2\right)$, both absorbance and fluorescence intensity increase due to a better solubilization of the porphyrin, together with narrowing of the Soret band in the red region. Absorption is also marked by the appearance of a shoulder around $405 \mathrm{~nm}$ in the Soret band which becomes a defined peak and maximum for that band at $\omega_{0}=10$ similar to what is observed in excitation spectra obtained at $670 \mathrm{~nm}$, Fig. 6A. Similarly, in the emission this is followed by the increase of a shoulder around $665 \mathrm{~nm}$ which is also a peak at $\omega_{0}=10$, Fig. 6B. Curiously, further addition of water seems to revert this picture by the decrease in the 405 and $663 \mathrm{~nm}$ peaks and a blue shift in both the monomer absorption and fluorescence maxima. Hence, until up to $\omega_{0}=10 \mathrm{PMet}_{\mathrm{CH}_{3}}$ and PPhe have similar responses to the water increase possibly favouring the formation of H-type aggregates. When water-pools are formed, water has properties closer to those of free water, thus favouring PPhe partition more to that water than $\mathrm{PMet}_{\mathrm{CH}_{3}}$. This is in agreement with spectral shift changes observed for PPhe (and not for $\mathrm{PMet}_{\mathrm{CH}_{3}}$ ) to the blue (as foreseen by solvatochromism data in neat solvents).

Fluorescence decays are consistent with steady-state data, Table 2, in as much as that only two exponentials are due to fit the decay in the absence of water, whereas when water is present then a third component must be taken into account. The lifetime components obtained at $\omega_{0}=0$ are similar to those detected in neat solvents like dioxane. The third component and short-lived one $\left(\tau_{1}=0.3 \mathrm{~ns}\right)$ is strictly related to the interaction with water and aggregate formation. The presence of water also leads to a decrease in the monomer lifetime specially at $\omega_{0}>10$ from $\tau_{1}=11.2-10.7 \mathrm{~ns}$, which tends to the value in water at neutral $\mathrm{pH}(\tau=9.3 \mathrm{~ns})$ by opposition to what had been observed for $\mathrm{PMet}_{\mathrm{CH}_{3}}$, Fig. 7. In common for these two porphyrins seems to be the fact that the intermediate component, which appears in all systems, has an important contribution in AOT RM increasing with $\omega_{0}$, being the dominant one in the case of PPhe at high $\omega_{0}$.

\subsubsection{Dependence on AOT concentration}

The surfactant concentration previously kept constant is now allowed to change keeping $\omega_{0}$ fixed. In this case we will be varying the concentration of micelles while before it was the size of each micelle that increased with $\omega_{0}$.

In the absence of water, at [AOT] around the $\mathrm{cmc}\left(\sim 1 \times 10^{-3}\right.$ to $5 \times 10^{-3} \mathrm{M}$ ) [20] the absorption and fluorescence spectra resemble that at high $\omega_{0}$ (or $\omega_{0}=10$ in the case of PPhe), i.e. a broad Soret band with a shoulder around $405 \mathrm{~nm}$ and the prevalence of the fluorescence maxima at $670 \mathrm{~nm}$. The increase of [AOT] leads to a substantial solubility enhancement of both

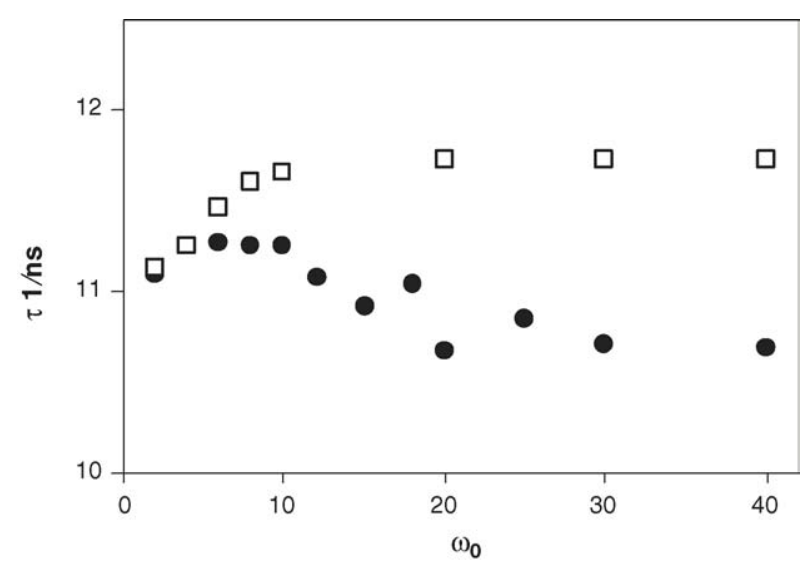

Fig. 7. Long-lived component dependence on $\omega_{0}$ obtained from tri-exponential fittings to fluorescence decays of $\mathrm{PMet}_{\mathrm{CH}_{3}}(\square)$ and PPhe $(\bullet)$ in AOT RM. 

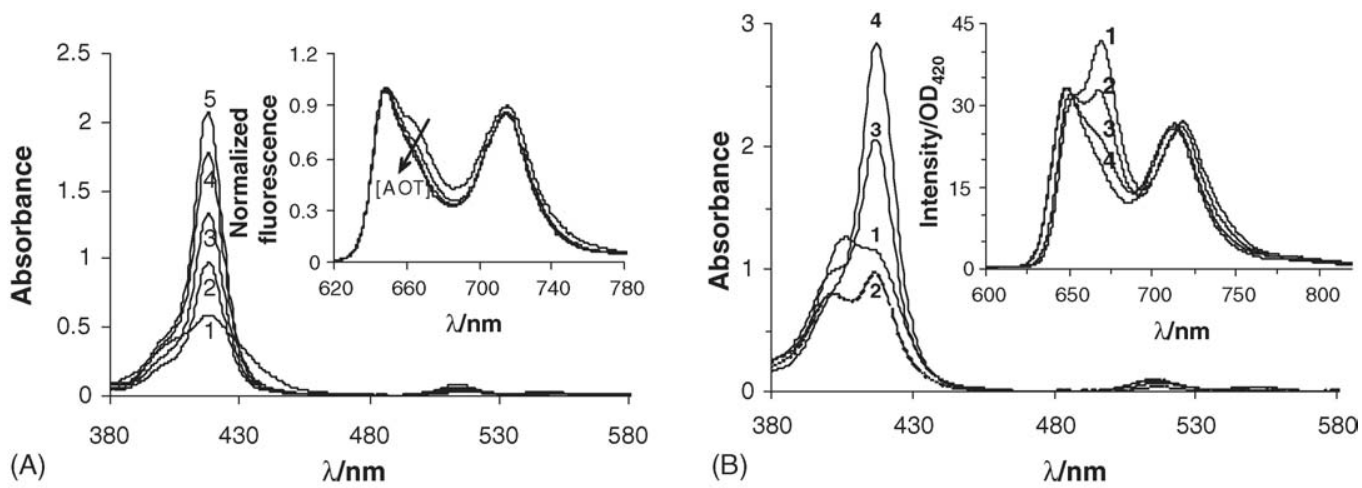

Fig. 8. Absorption and fluorescence spectra of (A) $\mathrm{PMet}_{\mathrm{CH}_{3}}$ at [AOT]: $0.01 \mathrm{M}, 1 ; 0.05 \mathrm{M}, 2 ; 0.075 \mathrm{M}, 3 ; 0.1 \mathrm{M}, 4 ; 0.35 \mathrm{M}, 5$; and (B) PPhe at [AOT]: 0.01 M, 1; $0.05 \mathrm{M}, 2 ; 0.1 \mathrm{M}, 3 ; 0.5 \mathrm{M}, 4$; in AOT RM with fixed $\omega_{0}=30$ ([Porphyrin] $=1 \mu \mathrm{M} ; \lambda_{\mathrm{exc}}=420 \mathrm{~nm}$ ).

porphyrins together with the narrowing in the Soret region and the appearance of the absorption and fluorescence spectra corresponding to the monomeric species. Since the solubility of these porphyrins is extremely low in iso-octane, a non-covalent interaction between the porphyrins and AOT is likely to take place which seems to stabilize aggregates in the same way as it happens with the aggregates formed in the micellar system in the presence of water.

The effect of $[\mathrm{AOT}]$ on the aggregation pattern of both porphyrins was followed also in the presence of water at $\omega_{0}=5$ and 30 showing a similar trend to that observed in its absence, Fig. 8 . In the case of $\mathrm{PMet}_{\mathrm{CH}_{3}}$, Fig. 8A, at low [AOT] the spectra present a broad Soret band (broader at $\omega_{0}=30$ ) which tends to that of the monomer followed by a significant concomitant increase of absorbance. No further changes seem to occur above $0.1 \mathrm{M}$ ([AOT]), inset Fig. 8A. Whereas, in the case of PPhe, due to its higher water solubility, the main effect is the de-aggregation process rather than an increase in solubility upon micellar concentration increase, Fig. 8B.

By increasing the surfactant concentration one increases the concentration of micelles, while the increase of the water amount keeping [AOT] constant has the opposite effect. Therefore, the amount of porphyrin per micelle changes in both cases. A plot of the ratio of absorbance read at 420 and $405 \mathrm{~nm}(R)$ as a function

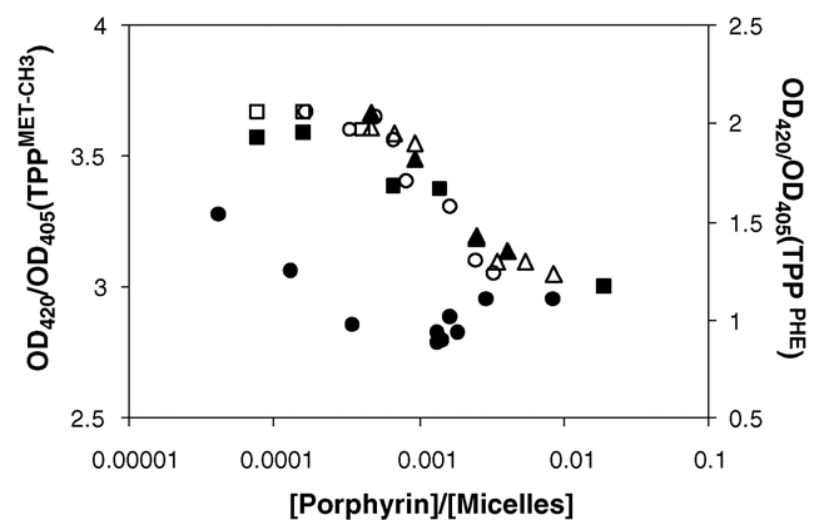

Fig. 9. Dependence of porphyrin ( $\mathrm{PMet}_{\mathrm{CH}_{3}}$, open symbols; PPhe, closed symbols) absorbance ratio $420: 405 \mathrm{~nm}$ on the amount of probe per micelle of AOT/iso-octane/water: $(\bigcirc, \boldsymbol{\bullet})$ varied $\omega_{0} ;(\square, \boldsymbol{\square})$ varied [AOT], $\omega_{0}=5$; $(\triangle$, ム) varied [AOT], $\omega_{0}=30$ of the amount of porphyrin $\left(\mathrm{PMet}_{\mathrm{CH}_{3}}\right)$ per micelle (assuming a location essentially in the micellar region) shows that all data fall in the same line, within experimental error, and that $R$ decreases as more porphyrin exists per micelle, Fig. 9.

In the case of PPhe, this trend is transposed to lower ratios values, i.e. the amount of aggregated species is always more for this porphyrin than for the former one. Moreover, for PPhe the size of the micelle seems to be important since in this case the porphyrin can also solubilize in the water-pools. Thus, bigger pools increase the distances between probes and increases contribution from monomeric species.

\section{Discussion}

Data reported here point to a complex pattern of aggregation for some derivatized porphyrins with aminoacids-phenylalanine with a non polar side chain and methionine with a polar side chain. The sterification of the acid function with a methyl group increases hydrophobicity and decreases solubility in water and in AOT RM, as one infers by comparison of data obtained with PPhe and $\mathrm{PMet}_{\mathrm{CH}_{3}}$. Data obtained with the latter in AOT RM are not reproducible within experimental error, due to strong adsorption to the walls of volumetric flasks and cuvettes. Therefore, we present data in AOT RM which concerns only the non-methylated form of PPhe and that of $\mathrm{PMet}_{\mathrm{CH}_{3}}$. In spite of having the ester function rather than the acid, the presence of the thio-ether group in the latter facilitates its incorporation in the RM.

Since these porphyrins have hydrophobic characteristics it is expected that they would self-aggregate in a process induced simply by changing the amount of water present in the systems under study. This was the case observed for $\mathrm{PMet}_{\mathrm{CH}_{3}}$ in dioxane-water mixtures. The absence of an isosbestic point in absorption spectra obtained at different water concentrations indicates that this is not a simple one-step equilibrium suggesting the coexistence of other species beyond monomers or dimers. In the case of benzoporphyrin-1,3-diene dimethyl ester, the type of aggregates induced in aqueous-solvent mixtures depended on the solvent nature and polarity: dimers could be found in DMSO and acetonitrile whereas in dioxane, ethanol and methanol mixtures multiple equilibria took place and trimers 
were also assumed present [21]. Small aggregates are also expected to be formed in the case of $\mathrm{PMet}_{\mathrm{CH}_{3}}$ taking into account the low signals obtained in RLS. This technique is extremely dependent on aggregate size, the signal being intensified when there is a strong coupling between the transition dipole moments of the porphyrin monomers [22].

\subsection{Effect of encapsulation in AOT RM}

A comparison of the data obtained for $\mathrm{PMet}_{\mathrm{CH}_{3}}$ in the dioxane-water mixtures and in AOT RM shows that aggregation in the former is detected at very high water concentrations $(\sim 44 \mathrm{M})$ while in AOT RM changes in absorption and fluorescence are observed at much lower water concentrations $(\sim 0.5 \mathrm{M})$. Since this porphyrin is soluble in Dx there must be a preferential solvation by the organic solvent, whereas in AOT RM this porphyrin cannot be located in the apolar solvent (where it is not soluble) but rather in the interface. Under these conditions the local concentration of water sensed by the molecule is much higher than that sensed in the mixtures, leading to aggregation of the porphyrin even at low $\omega_{0}$.

Different types of porphyrin aggregates can thus, be found in these RM as represented in Scheme 2. At $\omega_{0}=0$, the absorption spectra of the porphyrins under study show a broadening of the Soret band in the order $\mathrm{PMet}_{\mathrm{CH}_{3}}<\mathrm{PPhe}$, and larger than in the correspondent spectra in DMSO where it is assumed that only monomer exists. Since this broadening is related to porphyrin aggregation, the monomer solubility in RM in the absence of water depends on the polarizability of the substituent aminoacid groups. In the case of $\mathrm{PMet}_{\mathrm{CH}_{3}}$, monomers prevail at the interface whereas for PPhe, co-existence of non-fluorescent aggregates must occur in view of a narrower excitation spectrum compared to that of absorption.

The increase in $\omega_{0}$ is followed by an increase in the reverse micelle size together with micelle concentration decrease. Under these conditions, spectral characteristics assigned to aggregates' presence become increasingly important at higher $\omega_{0}$. Again differences are evident between the porphyrins studied. In general, $\mathrm{PMet}_{\mathrm{CH}_{3}}$ showed absorption spectra with increasing absorbance at $\sim 405 \mathrm{~nm}$ and data analysis pointed to the possibility of partition between interface and vicinal hydration water molecules, the latter contributing to porphyrin aggregation. By contrast to a growing contribution of aggregates of $\mathrm{PMet}_{\mathrm{CH}_{3}}$ with $\omega_{0}$, a maximum is detected for PPhe at $\omega_{0}=10$ where the Soret absorption band has the maximum at $405 \mathrm{~nm}$ and fluorescence spectrum has maxima at $\sim 670 \mathrm{~nm}$ (a shoulder at $655 \mathrm{~nm}$ ) and $720 \mathrm{~nm}$. These aggregates are fluorescent since excitation at shorter $(400 \mathrm{~nm})$ and longer $(430 \mathrm{~nm})$ wavelengths cause an increase in the intensities collected at $670 \mathrm{~nm}$. The fact that excitation spectra of PPhe are again narrower than the correspondent absorption ones (but almost superimposed in the case of $\mathrm{PMet}_{\mathrm{CH}_{3}}$ ) leads us to infer the presence of non-fluorescent aggregates for the former also in the presence of water, see Scheme 2B. At $\omega_{0}=10$ and above, the water encapsulated begins to have characteristics of free water thus contribution from monomeric PPhe becomes more important and spectra show absorbance of Soret band and fluorescence emission maxima, respectively at, 417, 651 and $713 \mathrm{~nm}$. This can be interpreted in terms of specific interactions
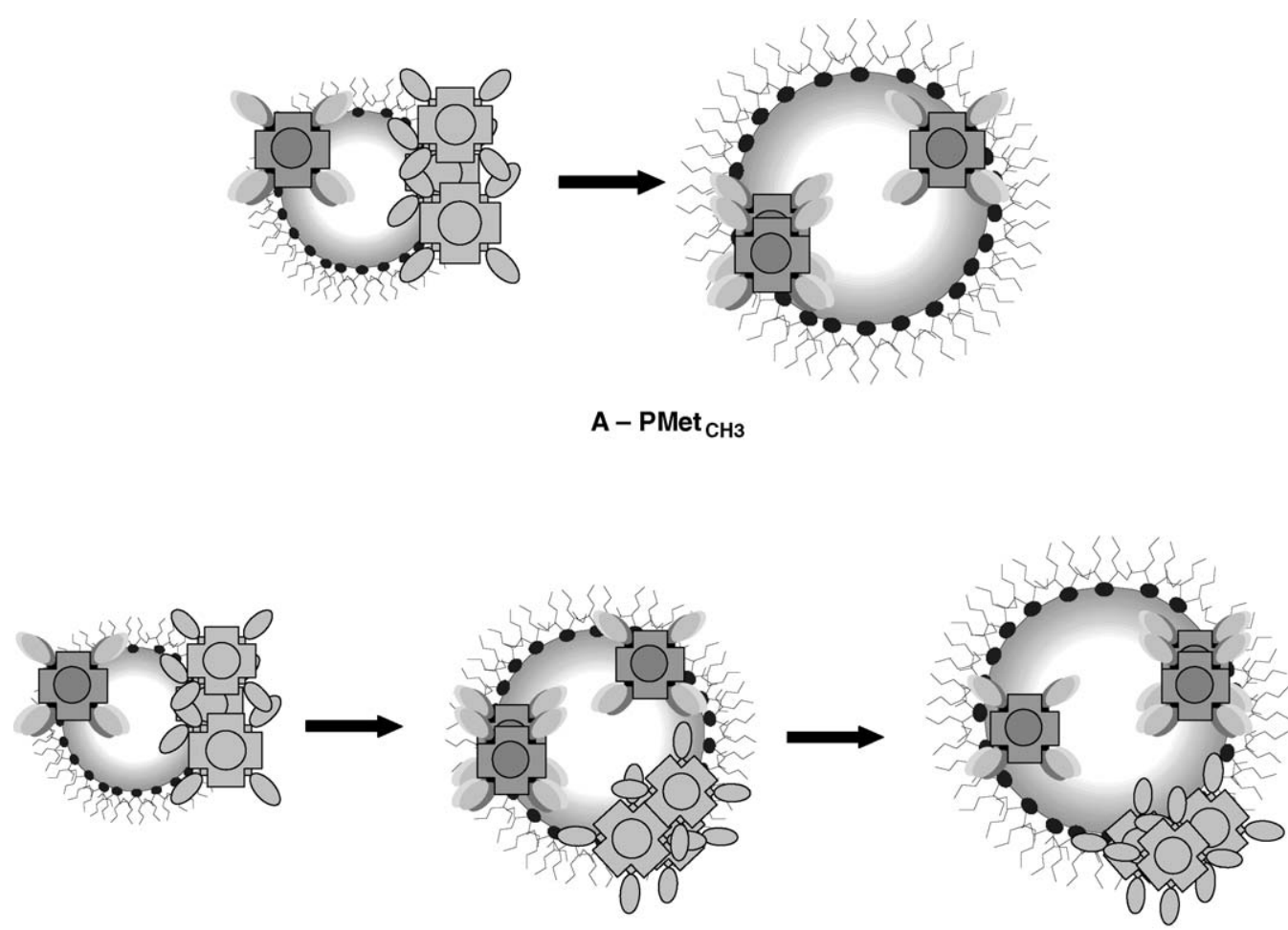

B - PPhe

Scheme 2. 
possibly hydrogen bond-type involving the acid group in the phenylalanine substituent and water, which in the case of the other porphyrin studied $\left(\mathrm{PMet}_{\mathrm{CH}_{3}}\right)$ is methylated. On the other hand, porphyrin aggregates could be stabilized by intramolecular H-bonding between the oxygen and hydrogen of neighbor porphyrins.

Another interesting feature is the fact that spectral properties of both $\mathrm{PMet}_{\mathrm{CH}_{3}}$ and PPhe aggregates in RM at high $\omega_{0}$ resemble those obtained at low concentration of AOT and water, which suggests the possibility of an interaction between porphyrin and AOT to form pre-micellar aggregates. These species are largely destabilized upon increase of surfactant concentration and consequently form RM.

\subsection{Comparison with other porphyrins}

Similar porphyrins also bearing the benzosulfamide group showed self-aggregation properties when encapsulated in these AOT RM [12b]. The effect of the chain length of the alkyl substituent linked to the benzosulfamide group was followed and similarities as well as distinctions can be established with the aminoacid derivatives. The longer the alkyl chain $(\mathrm{C}(4)$ and $\mathrm{C}(12)$ ) the more soluble the porphyrin would be in iso-octane due to a higher polarizability of the molecule. Therefore, porphyrin aggregation could be detected even in the absence of the surfactant which does not seem to occur in the case of the aminoacid substituents. Upon addition of AOT, the spectra obtained point to the prevalence of contributions from monomeric porphyrin in the case of PC12 which decrease for PC4 and are even less important for $\mathrm{PC} 0$. The presence of water favors aggregation in the case of PC4 and PC12 similarly to what was found here for PMet $_{\mathrm{CH}_{3}}$ and PPhe. However, the small de-aggregation detected for PC0 find similarities with PPhe at $\omega_{0}>10$, and confirms the establishment of hydrogen bonding interactions which for the former involve the terminal amine groups of the porphyrin.

\subsection{Aggregate type}

The aggregate molecular structure can be inferred from electronic absorption data since monomer molecules are arranged in a way that interactions between transition dipole moments of neighbor molecules are strong causing alterations in the absorption spectra of the aggregates. The exciton theory [6] can be applied to interpret these spectral changes. This theory suggests that two limiting cases may exist: (1) when the angle between the transition moments and the line that joins the molecular centers, $\theta$, is $0^{\circ}$, aggregates with this lateral arrangement (headto-tail) are called J-aggregates; (2) when $\theta=90^{\circ}$, the dipole moments of the monomeric units are aligned in parallel planes (face-to-face) the so-called $\mathrm{H}$-aggregate. Although some of these aggregates can theoretically emit, their relative quantum yield would be much smaller than that of the monomer. As mentioned above these two cases of aggregates correspond to extreme ideal geometries and in general the aggregate adopts structures with intermediate angles. Indeed, broadening of the Soret band in porphyrin aggregates is well known [23] and the occurrence of a sharp J-band is relatively rare. A good example of the latter is the case of TSPP, meso-tetrakis (sulfonatephenyl) porphine, which has recently been shown to be able to form highly ordered J-aggregate structures in AOT RM at acidic high water contents [24] whereas $\mathrm{H}$-aggregates are promoted at low $\omega_{0}$ independently of water $\mathrm{pH}[24 \mathrm{~b}, 25]$.

Different types of aggregates can be formed and differentiated from the intensity of RLS signals. Indeed, the strong intensity of those signals obtained for PC0 and PC4 in the absence of water and for PC12 at $\omega_{0}=40$, were associated to structures much bigger than those assigned here for $\mathrm{PMet}_{\mathrm{CH}_{3}}$ and PPhe in the presence of water, judged from the small RLS signals. PC0 and PC4 are present as J-aggregates whereas in PC12 the porphyrin aggregates are stacked in a co-facial manner. In our case, nonspecific aggregates with small dimensions and $\mathrm{H}$-aggregates are likely to be formed for both porphyrins under certain conditions in AOT RM. These aminoacid derivatized porphyrins establish weak hydrophobic interactions as well as steriochemical constraints due to the nature of the aminoacid substituents which may restrict the order and growth of the aggregates.

\section{4. $p H_{\text {ext }}$ effect}

The $\mathrm{pH}$ of the water added to the AOT RM was changed from 3.5 to 6.0 and 9.0 so that the effect of $\omega_{0}$ could be followed for the three main prototropic species of PPhe. Briefly, besides the increase of solubility with the addition of water, a common feature is the fact that aggregation is favoured until $\omega_{0}=10$ in the order $\mathrm{pH} 9 \geq 6 \gg 3$, and it is disfavoured above that $u_{0}$. Since solubility increases in a different manner $\mathrm{pH}$ $3 \geq 9>6$, the differences may be assigned to electrostatic interactions with the surfactant headgroups: the di-cationic species ( $\mathrm{pH} 3.5)$ will locate closer to the interface due to favourable interactions and thus will aggregate less and $\mathrm{PPhe}^{+}$data will vary less with $\omega_{0}$ increase; the tetra-anionic species ( $\mathrm{pH} 9.0$ ) will move away more from the interface due to repulsive interactions and will have a higher solubility in water thus more aggregates will also be found. At this $\mathrm{pH}$, some J-aggregates seem to be favoured, especially in free solution, as compared to $\mathrm{H}$ aggregates which are predominant in AOT RM. Nevertheless, at all $\mathrm{pH}$ studied the characteristics observed at the higher $\omega_{0}$ are still far from those in the corresponding free aqueous solution. An important feature to take into consideration is that due to the ionization of the surfactant polar headgroups, there is a high concentration of electric charges within the water in RM and consequently local $\mathrm{pH}$ differs from that of bulk water. Anionic surfactants usually decrease the apparent $\mathrm{pH}$ of the encapsulated water especially at low $\omega_{0}$. The differences between the entrapped water and bulk water are smaller towards the center of the water core, as the effect of surfactant layer becomes weaker [26].

In the case of $\mathrm{PMet}_{\mathrm{CH}_{3}}$ only two species will be present: dicationic at $\mathrm{pH} 3.5$ and neutral species at $\mathrm{pH} 6.0$ and 9.0. The latter serves just to check for changes in the AOT RM system upon $\mathrm{pH}$ increase which do not seem to occur since the spectral data at both $\mathrm{pH}$ are identical. In the case of the di-cation, almost no aggregated species could be detected, similarly to $\mathrm{PPhe}^{+}$ the preferential location at the interface prevents aggregation. 
However, in contrast to $\mathrm{PPhe}^{+}$, a quenching effect is observed with increasing water contents at both $\mathrm{pH}$ 's.

\subsection{Fluorescence lifetimes}

As stated before, molecular aggregation can drastically decrease fluorescence quantum yields and decay times [7c,27]. However, the decays were always bi-exponential in organic solvents and in dioxane-water mixtures where a shorter component was also present $\sim 2.6-4.0 \mathrm{~ns}$, contributing ca. $4 \%$ to the overall decay. In AOT RM even at $\omega_{0}=0$ there is some water present and thus, contribution from these two components is also obtained. When the concentration of water is increased either in the AOT RM or in dioxane-water mixtures $\left(x_{\mathrm{H}_{2} \mathrm{O}}>0.96\right)$, a third short-lived component, $\sim 0.3 \mathrm{~ns}$ is necessary to account satisfactorily for the decay. The contribution of the latter greatly increases with water addition in the mixtures (from 2 to $17 \%$ ) whereas in AOT RM in the presence of water its contribution is $\sim 2 \%$. This component could be due to specific interactions between the porphyrins and water. In fact, in free aqueous solutions the decays are always best fitted using tri-exponential functions.

The monomer lifetime for $\mathrm{PMet}_{\mathrm{CH}_{3}}$ does not seem to be affected by water increase in AOT RM whereas, in the case of PPhe it decreases and at $\omega_{0}=30$ it almost reaches the value in free aqueous solution $(\sim 9.8 \mathrm{~ns}$ at $\mathrm{pH} 6)$. This is in agreement with the spectral differences found and points to a bigger displacement of PPhe into the water-pools as compared to a more interfacial location for $\mathrm{PMet}_{\mathrm{CH}_{3}}$. For both porphyrins, the contribution of the component assigned to aggregates increases upon water addition in opposition to what occurs when AOT concentration is increased.

\section{Conclusions}

Two derivatized aminosulfonyl porphyrins, $\mathrm{PMet}_{\mathrm{CH}_{3}}$ and PPhe, were studied in solvents, aqueous mixtures and in AOT RM. A complex pattern of aggregation could be detected which was much influenced by the amount of water present in the system and by the nature of the aminoacid substituent. At $\omega_{0}=0$, both porphyrins prevail as monomers although non-fluorescent aggregates seem to co-exist with PPhe. The addition of water leads to the appearance of a shoulder in the absorption Soret band around $405 \mathrm{~nm}$ and in emission at $670 \mathrm{~nm}$ which increases concomitantly in the case of $\mathrm{PMet}_{\mathrm{CH}_{3}}$. By contrast, for PPhe these are well defined peaks whose contribution increases until waterpools are formed in the system where monomers are favored, well supported by the measured fluorescence lifetime which is identical to that obtained for PPhe monomer in water at $\mathrm{pH} 6$.

The PPhe with hydrophobic moiety seems to locate deeper in the water-pools of AOT RM than $\mathrm{PMet}_{\mathrm{CH}_{3}}$ with the polar methionine group due to the ionic character of the acid function in the former whereas in the latter the methyl ester prevents specific interactions with water. The results described bring an additional contribution to the possibity of using the AOT RM system to tune the optical properties of porphyrins by varying the water and micellar concentration, as it was recently reported by us for the case of TSPP [24b] and other alkyl derivatized aminosulfonyl porphyrins [12b].

\section{Acknowledgements}

This work was supported by CQE4/FCT and project POCTI/QUI/57387/2004. The authors thank Professor A.L. Maçanita for some help in the fluorescence lifetime measurements. S.M. Andrade, D.M. Togashi and C. Teixeira thank FCT for BPD grants 9439/2002, 5739/2001 and BD grant $16328 / 2004$, respectively.

\section{References}

[1] (a) J.-M. Lehn, in: R. Ungaro, E. Dalcanale (Eds.), Supramolecular Science: Where It Is and Where It Is Going, Kluwer Academic Publishers, 1999;

(b) R. Bonnett, Chem. Soc. Rev. 24 (1995) 19-33.

[2] W.I. White, in: D. Dolphin (Ed.), The Porphyrins, vol. V, Academic Press, New York, 1979.

[3] (a) P.W. Bohn, Ann. Rev. Phys. Chem. 44 (1993) 37-60; (b) E.W. Knapp, Chem. Phys. 85 (1984) 73-82.

[4] A.V. Udal'tsov, L.A. Kazarin, A.A. Sweshnikov, J. Photochem. Photobiol. A: Chem. 151 (2002) 105-119.

[5] (a) I.J. MacDonald, T.J. Dougherty, J. Porphyr. Phthalocya. 5 (2001) 105-129;

(b) D. Kessel, P. Thompson, K. Saatio, K.D. Nantwi, Photochem. Photobiol. 45 (1987) 787-790.

[6] M. Kasha, H.R. Rawls, M. El-Bayoumi, Pure Appl. Chem. 11 (1965) 371.

[7] (a) O. Ohno, Y. Kaizu, H. Kobayashi, J. Chem. Phys. 99 (1993) 4128-4139;

(b) D.L. Akins, H.-R. Zhu, C. Guo, J. Phys. Chem. 98 (1994) 3612-3618;

(c) N.C. Maiti, S. Mazumdar, N. Periasamy, J. Phys. Chem. B 102 (1998) 1528-1538;

(d) S.M. Andrade, S.M.B. Costa, Biophys. J. 82 (2002) 1607-1619.

[8] (a) P.J. Collings, E.J. Gibbs, T.E. Starr, O. Vafek, C. Yee, L.A. Pomerance, R.F. Pasternack, J. Phys. Chem. B 103 (1999) 8474-8481;

(b) N. Micali, F. Mallamace, A. Romeo, R. Purrello, L.M. Scolaro, J. Phys. Chem. B 104 (2000) 5897-5904;

(c) S.C.M. Gandini, E.L. Gelamo, R. Itri, M. Tabak, Biophys. J. 85 (2003) 1259-1268;

(d) R. Rotomskis, R. Augulis, V. Snitka, R. Valiokas, B. Liedberg, J. Phys. Chem. B 108 (2004) 2833-2838.

[9] A.J.F.N. Sobral, S. Eleouet, N. Rousset, A.M.D.A.R. Gonsalves, O. Le Meur, L. Bourré, T. Patrice, J. Porphyr. Phthalocya. 5 (2001) 105129.

[10] (a) J.-Y. Winum, J.-M. Dogné, A. Casini, X. de Leval, J.-L. Montero, A. Scozzafava, D. Vullo, A. Innocenti, C.T. Supuran, J. Med. Chem. 48 (2005) 2121-2125;

(b) A. Scozzafava, T. Owa, A. Mastrolorenzo, C.T. Supuran, Curr. Med. Chem. 10 (2003) 925-953.

[11] (a) Ph. De Groote, P.G. Rouxhet, J. Devaux, P. Godard, Appl. Spectrosc. 55 (2005) 877-887;

(b) J.M. Langenham, J.D. Fisk, S.H. Gellman, Org. Lett. 3 (2001) 2559-2562.

[12] (a) D.M. Togashi, S.M.B. Costa, A.J.F.N. Sobral, A.M.D'A.R. Gonsalves, Chem. Phys. 300 (2004) 267-275; (b) D.M. Togashi, S.M.B. Costa, A.J.F.N. Sobral, A.M.D'A.R. Gonsalves, J. Phys. Chem. B 108 (2004) 11344-11356.

[13] (a) M. Belletête, M. Lachapelle, G. Durocher, J. Phys. Chem. 94 (1990) 5337;

(b) E.C.C. Melo, S.M.B. Costa, A.L. Maçanita, H. Santos, J. Colloid Interf. Sci. 141 (1991) 439; 
(c) S.M. Andrade, S.M.B. Costa, Phys. Chem. Chem. Phys. 1 (1999) 4213-4218;

(d) C.A.T. Laia, S.M.B. Costa, Phys. Chem. Chem. Phys. 1 (1999) 4409-4416.

[14] P.M.R. Paulo, R. Gronheid, F.C. De Schryver, S.M.B. Costa, Macromolecules 36 (2003) 9135-9144.

[15] (a) M. Baur, M. Nicol, J. Chem. Phys. 44 (1966) 3337;

(b) N. Mataga, T. Kubota, Molecular Interaction and Electronic Spectra, Marcel Dekker, New York, 1970;

(c) N. Ghoneim, P. Suppan, Spectrochim. Acta, Part A 51 (1995) 1043.

[16] I. Renge, Chem. Phys. Lett. 185 (1991) 231-236.

[17] J.N. Nayak, M.I. Aralaguppi, B.V. Kumar Naidu, T.M. Aminabhavi, J. Chem. Eng. Data 49 (2004) 468-474.

[18] T.L.C. Figueiredo, R.A.W. Johnstone, A.M.P. SantAna Sorensen, D. Burget, P. Jacques, Photochem. Photobiol. 69 (1999) 517-528.

[19] P. López-Cornejo, S.M.B. Costa, Langmuir 14 (1998) 2042-2049.

[20] P.R. Majhi, S.P. Moulik, J. Phys. Chem. B 103 (1999) 5977.

[21] F.I. Simplicio, R.R.D. Soares, F. Maionchi, O. Santin, N. Hioka, J. Phys. Chem. A 108 (2004) 9384-9389.

[22] (a) R.F. Pasternack, P.J. Collings, Science 269 (1995) 935;

(b) N. Micali, F. Mallamace, M. Castriciano, A. Romeo, L.M. Scolaro, Anal. Chem. 73 (2001) 4958.
[23] (a) J. Zimmermann, U. Siggel, J.-H. Furhop, B. Roeder, J. Phys. Chem. B 107 (2003) 6019;

(b) M.Y. Choi, J.A. Pollard, M.A. Webb, J.L. McHale, J. Am. Chem. Soc. 125 (2003) 810;

(c) H. Garcia-Ortega, J.L. Bourdelande, J. Crusats, Z. El-Hachemi, J.M. Ribó, J. Phys. Chem. B 108 (2004) 4631.

[24] (a) M.A. Castriciano, A. Romeo, V. Villari, N. Micali, L.M. Scolaro, J. Phys. Chem. B 108 (2004) 9054; (b) S.M. Andrade, S.M.B. Costa, Chem. Eur. J. (2005) 000.

[25] M.A. Castriciano, A. Romeo, V. Villari, N. Angelini, N. Micali, L.M. Scolaro, J. Phys. Chem. B 109 (2005) 12086.

[26] (a) O.A. El Seoud, A.M. Chinelatto, J. Colloid Interf. Sci. 95 (1983) 163 ;

(b) C. Oldfield, B.H. Robinson, R.B. Freedman, J. Chem. Soc., Faraday Trans. 86 (1990) 833;

(c) S.P. Moulik, B.K. Paul, D.C. Mukerjee, J. Colloid Interf. Sci. 161 (1993) 72

[27] (a) D.L. Akins, S. Ozcelik, H. Zhu, C. Guo, J. Phys. Chem. 100 (1996) 14390 ;

(b) G.J. Smith, Photochem. Photobiol. 41 (1985) 123;

(c) M. Van der Auweraer, B. Verschuere, F.C. De Schryver, Langmuir 4 (1998) 583. 